\title{
Favorable mortality-to-incidence ratios of kidney Cancer are associated with advanced health care systems
}

Wen-Wei Sung ${ }^{1,2,3 \dagger}$, Shao-Chuan Wang ${ }^{1,2,3 \dagger}$, Tzuo-Yi Hsieh ${ }^{1,2,3}$, Cheng-Ju Ho ${ }^{2,4}$, Cheng-Yu Huang ${ }^{5}$, Yu-Lin Kao ${ }^{1,2,3}$, Wen-Jung Chen ${ }^{1,2,3}$ and Sung-Lang Chen ${ }^{1,2,3^{*}}$

\begin{abstract}
Background: The advancements in cancer therapy have improved the clinical outcomes of cancer patients in recent decades. However, advanced cancer therapy is expensive and requires good health care systems. For kidney cancer, no studies have yet established an association between clinical outcome and health care disparities.

Methods: We used the mortality-to-incidence ratio (MIR) for kidney cancer as a marker of clinical outcome to compare World Health Organization (WHO) country rankings and total expenditures on health/gross domestic product (e/GDP) using linear regression analyses.

Results: We included 57 countries based on data from the GLOBOCAN 2012 database. We found that more highly developed regions have higher crude and age-standardized rates of kidney cancer incidence and mortality, but a lower MIR, when compared to less developed regions. North America has the highest crude rates of incidence, but the lowest MIRs, whereas Africa has the highest MIRs. Furthermore, favorable MIRs are correlated with countries with good WHO rankings and high e/GDP expenditures ( $p<0.001$ and $p=0.013$, respectively).
\end{abstract}

Conclusions: Kidney cancer MIRs are positively associated with the ranking of health care systems and health care expenditures.

Keywords: Kidney cancer, Mortality, Incidence, Mortality-to-incidence ratio

\section{Background}

Cancer is a leading cause of death worldwide, and the burden continues to increase in both developed and less developed countries due to lifestyle behaviors, such as smoking, poor diet, and physical inactivity [1, 2]. Kidney cancer currently ranks as the seventh most common cancer in men and the tenth most common in women [3]. In 2012, the worldwide estimates for kidney cancer were 338,000 new cases (incidence: 2.4\%) and 143,000 deaths (mortality: 1.7\%) [3]. The geographic distribution of kidney cancer is highest in the Baltic countries and in Eastern European countries, such as the Czech Republic

\footnotetext{
* Correspondence: cshy650@csh.org.tw

tWen-Wei Sung and Shao-Chuan Wang contributed equally to this work. 'Department of Urology, Chung Shan Medical University Hospital, No.110, Sec. 1, Jianguo N. Rd., South Dist, Taichung City 402, Taiwan

${ }^{2}$ School of Medicine, Chung Shan Medical University, No.110, Sec. 1, Jianguo N. Rd., South Dist, Taichung City 402, Taiwan

Full list of author information is available at the end of the article
}

and Slovakia, and lowest in Africa and Asia, with the exception of Israel [4]. The mortality distribution also follows incidence patterns, with the highest death rates observed in Eastern Europe [4]. Renal cell carcinoma accounts for more than $90 \%$ of kidney malignancies, with the main subtype being clear cell renal cell carcinoma (70\%) [5].

The clinical outcomes of cancer treatment can be measured by the five-year survival rate, as well as partially by the mortality-to-incidence ratio (MIR) [6-12]. In the past 10 years, the incidence of renal cell carcinoma has increased in most countries [13]. By contrast, the mortality associated with this disease has been relatively stable worldwide, but is decreasing in Western Europe, the US, and Australia [13]. For example, the five-year relative survival rate for kidney cancer patients in the US in 2005-2011 was approximately $74 \%$, an increase from the rate of approximately $57 \%$ in the 1980 s

(c) The Author(s). 2018 Open Access This article is distributed under the terms of the Creative Commons Attribution 4.0 International License (http://creativecommons.org/licenses/by/4.0/), which permits unrestricted use, distribution, and 
$[1,2]$. These trends suggest that health care systems and health care expenditures are affecting the screening, treatment, and prognosis of kidney cancer.

We hypothesize that the MIR should be low in countries with better health care systems. Our primary goal in the present study was to identify the roles played by the level of human development, World Health Organization (WHO) rankings, and total expenditure on health/gross domestic product (e/GDP) in kidney cancer outcomes. Our secondary goal was to clarify the correlation between MIRs and the WHO ranking and e/GDP and to determine the association between e/GDP or WHO ranking and the crude rate or age-standardized rate (ASR) of kidney cancer incidence and mortality. Our results provide a general overview of the connection between MIR and health care disparities across countries.

\section{Methods}

The data were acquired as described previously $[6,12,14]$. In brief, the cancer epidemiologic data were obtained from the GLOBOCAN 2012 database, which is maintained by the International Agency for Research on Cancer (https:// www.iarc.fr/) [3]. Health care expenditures and life expectancies were obtained from the WHO World Health Statistics 2015, and the WHO rankings were obtained from the WHO World's Health Systems. We included 184 countries listed in the GLOBOCAN 2012 database. Countries that lacked WHO ranking data (22 countries) or that had little data available (a ranking of E-G for incidence or a ranking of 4-6 for mortality; 105 countries) were excluded.

The MIR is defined as the ratio of the crude rate of mortality to the disease incidence $[7,10]$. The method of statistical analyses was described previously $[6,14]$. We used linear regression and SPSS statistical software (SPSS, version 15.0, Inc., Chicago, IL, US) to evaluate the association between the MIRs and variants. $P$ values $<0.05$ were considered statistically significant. Scatter plots were produced using Microsoft Excel 2010.

\section{Results}

The incidence and mortality of kidney cancer are higher in more developed regions and in regions in the west

We first sought to understand the present global situation regarding kidney cancer by analyzing the crude rate and the ASR of kidney cancer incidence and mortality according to development level, WHO region, and continent (see Table 1). The crude rate of incidence and the cancer-related mortality rate worldwide are 4.8 and 2.0, respectively, for kidney cancer. Both rates tend to be higher in more developed regions (incidence: 16.1 vs. 2.4; mortality: 6.0 vs. 1.2 , respectively). The analysis based on WHO regions and continents indicated that the WHO European region had the highest crude rate of incidence and mortality (13.5 and 5.9, respectively), followed by the WHO Americas region (8.9 and 2.9,

Table 1 Summary of the number of cases, rates, and mortality-to-incidence ratios of kidney cancer according to region

\begin{tabular}{|c|c|c|c|c|c|c|c|}
\hline \multirow[t]{2}{*}{ Region } & \multicolumn{2}{|l|}{ Number } & \multicolumn{2}{|l|}{ Crude rate } & \multicolumn{2}{|c|}{ Age-standardized rate } & \multirow{2}{*}{$\begin{array}{l}\text { Mortality-to- } \\
\text { incidence ratio }\end{array}$} \\
\hline & Incidence & Mortality & Incidence & Mortality & Incidence & Mortality & \\
\hline World & 337,860 & 143,406 & 4.8 & 2.0 & 4.4 & 1.8 & 0.42 \\
\hline \multicolumn{8}{|l|}{ Development } \\
\hline More developed regions & 199,991 & 74,948 & 16.1 & 6.0 & 9.2 & 2.8 & 0.37 \\
\hline Less developed regions & 137,869 & 68,458 & 2.4 & 1.2 & 2.6 & 1.3 & 0.50 \\
\hline \multicolumn{8}{|l|}{ WHO region categories } \\
\hline WHO Africa region & 6725 & 5649 & 0.8 & 0.6 & 1.0 & 0.8 & 0.75 \\
\hline WHO Americas region & 85,005 & 27,949 & 8.9 & 2.9 & 7.3 & 2.2 & 0.33 \\
\hline WHO East Mediterranean region & 8952 & 6628 & 1.4 & 1.1 & 1.9 & 1.5 & 0.79 \\
\hline WHO Europe region & 121,629 & 52,816 & 13.5 & 5.9 & 8.3 & 3.1 & 0.44 \\
\hline WHO South-East Asia region & 17,050 & 11,399 & 0.9 & 0.6 & 1.1 & 0.7 & 0.67 \\
\hline WHO Western Pacific region & 98,473 & 38,951 & 5.3 & 2.1 & 4.1 & 1.5 & 0.40 \\
\hline \multicolumn{8}{|l|}{ Continent } \\
\hline Africa & 10,033 & 8169 & 0.9 & 0.8 & 1.2 & 1.0 & 0.89 \\
\hline Latin America and Caribbean & 21,183 & 11,308 & 3.5 & 1.9 & 3.5 & 1.8 & 0.54 \\
\hline Northern America & 63,822 & 16,641 & 18.2 & 4.7 & 11.7 & 2.6 & 0.26 \\
\hline Asia & 123,402 & 57,058 & 2.9 & 1.3 & 2.8 & 1.3 & 0.45 \\
\hline Europe & 115,252 & 49,025 & 15.5 & 6.6 & 8.8 & 3.1 & 0.43 \\
\hline Oceania & 4168 & 1205 & 11.0 & 3.2 & 8.0 & 2.0 & 0.29 \\
\hline
\end{tabular}

${ }^{a}$ the percentage in the ratio of the crude rate of mortalities and the crude rate of incidences 
respectively). North America had the highest crude rate of incidence (18.2), and Europe had the highest mortality rate (6.6). The ASR distribution showed a similar pattern, as the ASRs of incidence and mortality were 9.2 and 2.8 in more developed regions, with the highest values associated with the WHO European region (8.3 and 3.1, respectively) and the WHO Americas region (7.3 and 2.2, respectively). North America had the highest ASR of incidence (11.7), while Europe had the highest ASR of mortality (3.1), and both regions are developed.

\section{The kidney cancer mortality-to-incidence ratios are high in less developed regions}

We also investigated the MIRs to determine any association between this ratio and the outcomes of kidney cancer patients. The global kidney cancer MIR is 0.42 , with a higher rate in less developed regions (0.5). The WHO East Mediterranean region had the highest kidney cancer MIR (0.79), followed by the WHO Africa region (0.75). Among the continents, Africa had the highest MIR (0.89). High MIRs were therefore associated with less developed regions and with Africa.

World Health Organization ranking and total expenditure on health/GDP are significantly associated with kidney cancer mortality-to-incidence ratios

We sought to understand the observed differences between nations by including countries based on national data, WHO rankings, total expenditure on health/GDP (e/GDP), crude rate of incidence and mortality, the ASR of incidence and mortality, and life expectancy (Table 2). France was the highest WHO ranked country, whereas the US had the highest e/GDP (17.0\%). Among all the countries, the Czech Republic had the highest crude rate of incidence (22.7), and Estonia had the highest mortality rate (10.6). Of the 57 countries compared, Luxembourg had the lowest MIR (0.17). We further examined the correlation between the kidney cancer MIR and the WHO ranking and e/GDP (Table 2; Fig. 1). The WHO ranking and e/GDP showed a significant positive correlation with kidney cancer MIRs $\left(R^{2}=0.232, p<\right.$ $0.001 ; R^{2}=0.107, p=0.013$, respectively; Fig. 1 ).

\section{No significant correlation is evident between the World Health Organization ranking, crude rate, and age- standardized rate of incidence and mortality for kidney cancer}

Unexpectedly, we found no significant correlation between WHO ranking and the crude rate of incidence and mortality for kidney cancer $\left(R^{2}=0.058, p=0.071\right.$; $R^{2}=0.018, \quad p=0.317$, respectively; Additional file 1 : Figure S1A and B). Countries with a higher WHO ranking also showed no higher incidence or greater mortality rate in age-standardized groups $\left(R^{2}=0.032, p=0.185\right.$; $R^{2}=0.004, p=0.629$, respectively; Additional file 1 : Figure S1C and D).

\section{The association between total expenditure on health/GDP and the kidney cancer crude rate and age-standardized rate of incidence and mortality}

We also analyzed the correlation between e/GDP and crude rate and the ASR of incidence and mortality for kidney cancer (Additional file 2: Figure S2). The crude rate of incidence and mortality in these countries increased with increasing e/GDP $\left(R^{2}=0.237, p<0.001\right.$; $R^{2}=0.169, \quad p=0.001$, respectively; Additional file 2 : Figure S2A and B), and the same trend was seen for the association between e/GDP and the ASR of incidence $\left(R^{2}=0.187, p=0.001\right.$; Additional file 2: Figure S2C). However, no significant correlation was noted between e/GDP and the ASR of mortality $\left(R^{2}=0.053, p=0.084\right.$; Additional file 2: Figure S2D). In summary, the e/GDP had a significant correlation with the incidence and mortality crude rate of kidney cancer, while the ASR of mortality was not significantly correlated with e/GDP.

\section{Discussion}

To the best of our knowledge, this is the first article to explore the relationship between the MIRs of kidney cancer and WHO rankings, life expectancy, and e/GDP. Negative correlations between the WHO ranking and life expectancy and e/GDP (\%) would be understandable, as disability-adjusted life expectancy and fair financial contribution were two of the index factors on which the WHO ranking is based. High MIRs are observed in less developed countries for genitourinary malignancies [15]. In the present study, we found a positive correlation between WHO rankings and MIRs, in agreement with a previous study on colorectal cancer that showed similar results among the Organisation for Economic Co-operation and Development countries [10]. Sunkara et al. attributed this correlation to the better screening programs provided by countries with better WHO rankings for certain cancer such as colorectal cancer. However, there is no screen program for kidney cancer, the improved MIR might relate to the availability of medical service and health examination.

As with colorectal cancer, kidney cancer outcomes depend on early detection and proper intervention. The increased demand for abdominal imaging has led to an increase in the incidental detection of kidney masses, usually as small indolent cancers [16]. As a result, in the US, $63 \%$ of kidney cancers are diagnosed at a localized stage [17], and this directly affects outcome as the five-year survival rates show substantial differences among stages. The localized stage has the best prognosis, with a $92 \%$ five-year survival rate, while the distant stage 
Table 2 Summary of World Health Organization country rankings; total expenditure on health/GDP; life expectancy; and the kidney cancer incidence, mortality, and mortality-to-incidence ratios of selected countries

\begin{tabular}{|c|c|c|c|c|c|c|c|c|c|c|}
\hline \multirow[t]{2}{*}{ Country } & \multirow[t]{2}{*}{ Ranking } & \multirow[t]{2}{*}{$\begin{array}{l}\text { Total expenditure } \\
\text { on health/GDP (\%) }\end{array}$} & \multirow[t]{2}{*}{$\begin{array}{l}\text { Life } \\
\text { expectancy }\end{array}$} & \multicolumn{2}{|l|}{ Number } & \multicolumn{2}{|l|}{ Crude rate } & \multicolumn{2}{|c|}{$\begin{array}{l}\text { Age-standardized } \\
\text { rate }\end{array}$} & \multirow[t]{2}{*}{$\begin{array}{l}\text { Mortality-to- } \\
\text { incidence ratio }\end{array}$} \\
\hline & & & & Incidence & Mortality & Incidence & Mortality & Incidence & Mortality & \\
\hline France & 1 & 11.6 & 82 & 11,023 & 4186 & 17.4 & 6.6 & 9.7 & 2.8 & 0.38 \\
\hline Italy & 2 & 9.2 & 83 & 11,300 & 4203 & 18.5 & 6.9 & 8.7 & 2.5 & 0.37 \\
\hline Malta & 5 & 8.7 & 81 & 57 & 27 & 13.6 & 6.4 & 8.0 & 3.0 & 0.47 \\
\hline Singapore & 6 & 4.2 & 83 & 401 & 175 & 7.6 & 3.3 & 5.2 & 2.2 & 0.43 \\
\hline Spain & 7 & 9.3 & 83 & 6474 & 2295 & 13.8 & 4.9 & 7.9 & 2.2 & 0.36 \\
\hline Oman & 8 & 2.7 & 76 & 36 & 21 & 1.2 & 0.7 & 2.1 & 1.4 & 0.58 \\
\hline Austria & 9 & 11.1 & 81 & 1322 & 536 & 15.7 & 6.4 & 8.0 & 2.5 & 0.41 \\
\hline Japan & 10 & 10.3 & 84 & 16,830 & 8124 & 13.3 & 6.4 & 5.3 & 1.9 & 0.48 \\
\hline Norway & 11 & 9.3 & 82 & 798 & 263 & 16.1 & 5.3 & 9.3 & 2.5 & 0.33 \\
\hline Portugal & 12 & 9.9 & 81 & 1004 & 368 & 9.4 & 3.4 & 5.0 & 1.4 & 0.36 \\
\hline Iceland & 15 & 9.0 & 82 & 45 & 19 & 13.7 & 5.8 & 8.8 & 3.2 & 0.42 \\
\hline Luxembourg & 16 & 7.2 & 82 & 70 & 12 & 13.4 & 2.3 & 8.3 & 0.9 & 0.17 \\
\hline Netherlands & 17 & 12.7 & 81 & 2679 & 1463 & 16.0 & 8.8 & 8.8 & 4.0 & 0.55 \\
\hline United Kingdom & 18 & 9.3 & 81 & 9714 & 4150 & 15.5 & 6.6 & 8.2 & 3.0 & 0.43 \\
\hline Ireland & 19 & 8.9 & 81 & 571 & 230 & 12.5 & 5.0 & 8.4 & 3.0 & 0.40 \\
\hline Switzerland & 20 & 11.4 & 83 & 948 & 448 & 12.3 & 5.8 & 6.5 & 2.4 & 0.47 \\
\hline Belgium & 21 & 10.9 & 80 & 1763 & 728 & 16.3 & 6.7 & 8.7 & 2.7 & 0.41 \\
\hline Colombia & 22 & 6.8 & 78 & 1048 & 483 & 2.2 & 1.0 & 2.4 & 1.1 & 0.45 \\
\hline Sweden & 23 & 9.6 & 82 & 1125 & 635 & 11.8 & 6.7 & 6.4 & 2.6 & 0.57 \\
\hline Cyprus & 24 & 7.3 & 82 & 46 & 17 & 4.1 & 1.5 & 3.0 & 1.0 & 0.37 \\
\hline Germany & 25 & 11.3 & 81 & 18,615 & 7540 & 22.7 & 9.2 & 10.6 & 3.3 & 0.41 \\
\hline Israel & 28 & 7.4 & 82 & 1002 & 217 & 13.0 & 2.8 & 10.0 & 1.8 & 0.22 \\
\hline Canada & 30 & 10.9 & 82 & 5579 & 1739 & 16.1 & 5.0 & 9.3 & 2.5 & 0.31 \\
\hline Finland & 31 & 9.1 & 81 & 882 & 333 & 16.3 & 6.2 & 7.9 & 2.4 & 0.38 \\
\hline Australia & 32 & 8.9 & 83 & 3501 & 960 & 15.3 & 4.2 & 9.5 & 2.1 & 0.27 \\
\hline Chile & 33 & 7.3 & 80 & 1353 & 737 & 7.8 & 4.2 & 6.0 & 3.1 & 0.54 \\
\hline Denmark & 34 & 11.0 & 80 & 754 & 352 & 13.5 & 6.3 & 7.2 & 2.9 & 0.47 \\
\hline Costa Rica & 36 & 10.1 & 79 & 179 & 69 & 3.7 & 1.4 & 3.7 & 1.4 & 0.38 \\
\hline $\begin{array}{l}\text { United States of } \\
\text { America }\end{array}$ & 37 & 17.0 & 79 & 58,222 & 14,900 & 18.4 & 4.7 & 12.0 & 2.6 & 0.26 \\
\hline Slovenia & 38 & 9.4 & 80 & 400 & 171 & 19.6 & 8.4 & 11.1 & 3.9 & 0.43 \\
\hline Cuba & 39 & 8.6 & 78 & 517 & 271 & 4.6 & 2.4 & 3.1 & 1.5 & 0.52 \\
\hline New Zealand & 41 & 10.2 & 82 & 586 & 198 & 13.1 & 4.4 & 8.2 & 2.4 & 0.34 \\
\hline Bahrain & 46 & 4.4 & 77 & 23 & 7 & 1.7 & 0.5 & 2.6 & 1.0 & 0.29 \\
\hline Thailand & 47 & 4.5 & 75 & 1017 & 632 & 1.5 & 0.9 & 1.2 & 0.7 & 0.60 \\
\hline Czech Republic & 48 & 7.5 & 78 & 3313 & 1095 & 31.4 & 10.4 & 16.7 & 4.8 & 0.33 \\
\hline Malaysia & 49 & 4.0 & 74 & 611 & 255 & 2.1 & 0.9 & 2.4 & 1.0 & 0.43 \\
\hline Poland & 50 & 6.8 & 77 & 5244 & 2721 & 13.7 & 7.1 & 8.1 & 3.7 & 0.52 \\
\hline Jamaica & 53 & 5.6 & 74 & 31 & 20 & 1.1 & 0.7 & 1.1 & 0.7 & 0.64 \\
\hline Korea, Republic of & 58 & 7.6 & 82 & 5651 & 1264 & 11.6 & 2.6 & 8.0 & 1.6 & 0.22 \\
\hline Philippines & 60 & 4.4 & 69 & 1008 & 600 & 1.0 & 0.6 & 1.4 & 0.9 & 0.60 \\
\hline Slovakia & 62 & 8.1 & 76 & 1063 & 388 & 19.4 & 7.1 & 12.5 & 4.2 & 0.37 \\
\hline
\end{tabular}


Table 2 Summary of World Health Organization country rankings; total expenditure on health/GDP; life expectancy; and the kidney cancer incidence, mortality, and mortality-to-incidence ratios of selected countries (Continued)

\begin{tabular}{|c|c|c|c|c|c|c|c|c|c|c|}
\hline \multirow[t]{2}{*}{ Country } & \multirow[t]{2}{*}{ Ranking } & \multirow[t]{2}{*}{$\begin{array}{l}\text { Total expenditure } \\
\text { on health/GDP (\%) }\end{array}$} & \multirow[t]{2}{*}{$\begin{array}{l}\text { Life } \\
\text { expectancy }\end{array}$} & \multicolumn{2}{|l|}{ Number } & \multicolumn{2}{|l|}{ Crude rate } & \multicolumn{2}{|c|}{$\begin{array}{l}\text { Age-standardized } \\
\text { rate }\end{array}$} & \multirow[t]{2}{*}{$\begin{array}{l}\text { Mortality-to- } \\
\text { incidence ratio }\end{array}$} \\
\hline & & & & Incidence & Mortality & Incidence & Mortality & Incidence & Mortality & \\
\hline Egypt & 63 & 4.9 & 71 & 1740 & 1275 & 2.1 & 1.5 & 2.4 & 1.8 & 0.71 \\
\hline Uruguay & 65 & 8.6 & 77 & 465 & 243 & 13.7 & 7.2 & 9.4 & 4.4 & 0.53 \\
\hline $\begin{array}{l}\text { Trinidad } \\
\text { and Tobago }\end{array}$ & 67 & 5.5 & 71 & 32 & 18 & 2.4 & 1.3 & 2.3 & 1.1 & 0.54 \\
\hline Belarus & 72 & 5.0 & 72 & 1575 & 637 & 16.5 & 6.7 & 11.1 & 4.1 & 0.41 \\
\hline Lithuania & 73 & 6.7 & 74 & 773 & 309 & 23.5 & 9.4 & 13.2 & 4.9 & 0.40 \\
\hline Argentina & 75 & 6.8 & 76 & 4068 & 1998 & 9.9 & 4.9 & 8.0 & 3.6 & 0.49 \\
\hline Estonia & 77 & 5.9 & 77 & 284 & 142 & 21.2 & 10.6 & 11.7 & 4.6 & 0.50 \\
\hline Ukraine & 79 & 7.5 & 71 & 5240 & 2542 & 11.7 & 5.7 & 7.5 & 3.4 & 0.49 \\
\hline Mauritius & 84 & 4.8 & 74 & 53 & 25 & 4.0 & 1.9 & 4.2 & 2.2 & 0.48 \\
\hline Fiji & 96 & 4.0 & 70 & 4 & 3 & 0.5 & 0.3 & 0.4 & 0.4 & 0.60 \\
\hline Bulgaria & 102 & 7.4 & 75 & 881 & 470 & 11.9 & 6.4 & 6.9 & 3.3 & 0.54 \\
\hline Latvia & 105 & 5.9 & 74 & 449 & 225 & 20.1 & 10.1 & 10.9 & 4.7 & 0.50 \\
\hline Ecuador & 111 & 6.4 & 76 & 403 & 216 & 2.7 & 1.5 & 2.9 & 1.5 & 0.56 \\
\hline Brazil & 125 & 9.5 & 75 & 6255 & 3291 & 3.2 & 1.7 & 3.0 & 1.5 & 0.53 \\
\hline $\begin{array}{l}\text { Russian } \\
\text { Federation }\end{array}$ & 130 & 6.5 & 69 & 19,313 & 9025 & 13.5 & 6.3 & 8.9 & 3.8 & 0.47 \\
\hline $\begin{array}{l}\text { South African } \\
\text { Republic }\end{array}$ & 175 & 8.9 & 60 & 506 & 420 & 1.0 & 0.8 & 1.2 & 1.1 & 0.80 \\
\hline
\end{tabular}

${ }^{a}$ the percentage in the ratio of the crude rate of mortalities and the crude rate of incidences

has only a $12 \%$ five-year survival rate [17]. These numbers point to the importance of early detection of this disease. In general, this means that countries with better health care programs would be expected to have lower MIRs due to the availability of image survey such as sonography or computed tomography scan. This increases the incidental finding of renal mass and might relate to early diagnosis and good prognosis. This could then explain the observed association between WHO rankings and MIRs.
We also found negative correlations between WHO rankings and crude mortality and incidence rates, indicating higher rates in countries with better WHO rankings. One possible explanation is the inconsistency of access to medical care among different countries, as nations with worse WHO rankings are less likely to have good health care access. This means less abdominal imaging and less detection of early signs and symptoms of kidney cancer, so the incidence and mortality rates increase. Another explanation is the age distribution of
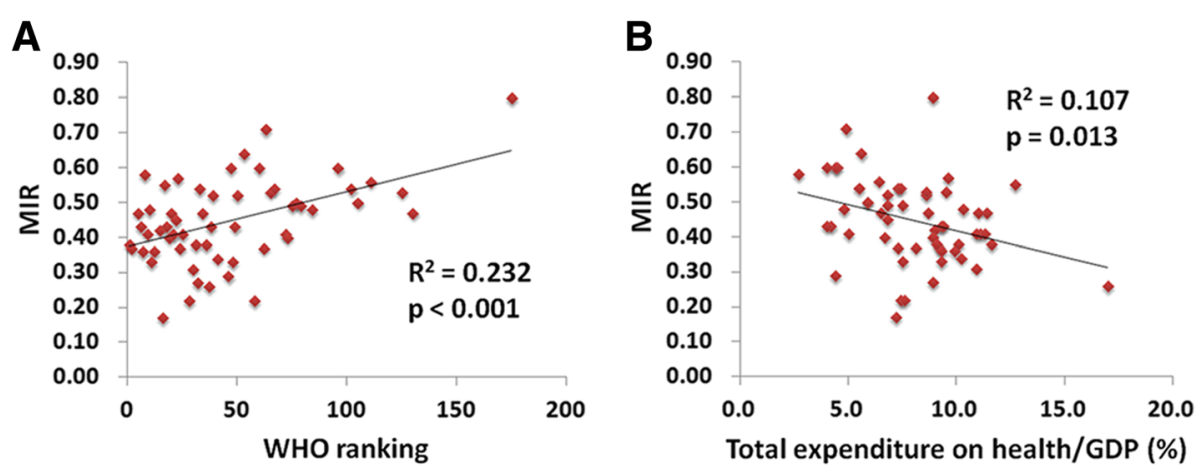

Fig. 1 The (a) World Health Organization country rankings and (b) total expenditures on health/GDP are significantly associated with the mortality-to-incidence ratio of kidney cancer 
this disease. Most cases are diagnosed between the ages of 60 and 70, with the median age being $65[18,19]$. Therefore, the populations of countries with longer life expectancy would have a greater risk of developing kidney cancer. As life expectancy correlates positively with WHO rankings and WHO rankings correlate negatively with mortality, the crude rates of incidence are understandable.

The impact of high health care expenditure on good MIRs for kidney cancer is multifactorial, as noted for other types of cancer $[6,11,12,14]$. Patients in countries with higher health care expenditure would have a greater chance of early malignancy detection and prompt curative treatment or less invasive surgery. From the perspective of surgical intervention for kidney cancer, patients with early $\mathrm{T}$ stage cancer would have a larger volume of healthy renal parenchyma for renal preservation, which might result in a better clinical outcome [20]. For partial nephrectomy, outcomes are more favorable for robotic surgery than for laparoscopic surgery in terms of a lower conversion rate to radical nephrectomy, favorable retention of renal function, and shorter warm ischemia time [21-23]. These features could partially explain the role of health expenditure in the MIR of kidney cancer.

Our study has some limitations. Since the GLOBCAN database provides national statistics information worldwide, the data quality should be further validated. Countries with low data quality or unknown data quality were excluded to avoid misleading effects of over diagnosis or other influences. Due to concerns about generating misleading MIRs, we did not include all the countries listed in the database. This resulted in incomplete data, which makes our results unreliable in the global context. Furthermore, we did not document the diagnosed stage and risk factors among countries, such as smoking, obesity, and hypertension rates. These risk factors may play crucial roles in explaining the incidence and mortality rates among countries and regions. In addition, we only examined cross-sectional data for a single year, so the actual disease trend may not be accurately presented. Another limitation is the use of WHO rankings. This grading system was established in 2000 , so it may not precisely reflect the current situation for health care systems in different countries, although the correlations with life expectancy and e/GDP speak to its credibility.

Despite these limitations, our study shows higher kidney cancer incidence and mortality rates in more developed regions and in countries with better WHO rankings. Moreover, the MIRs for these countries are negatively correlated with their WHO rankings for both genders. Based on the results, we suspect that the kidney cancer MIR might be an appropriate indicator for evaluating health care systems. The massive discrepancies in kidney cancer MIRs between countries and regions suggest a role for early detection and proper screening facilities in countries with higher MIR values.

\section{Conclusions}

Kidney cancer MIRs are associated with the ranking of health care systems and health care expenditures and therefore might be an indicator of health care disparities.

\section{Additional files}

Additional file 1: Figure S1. The association between the World Health Organization country ranking of total expenditures on health/GDP and the crude rates of (A) kidney cancer incidence and (B) kidney cancer-related mortality. The age-standardized rates of (C) kidney cancer incidence and (D) kidney cancer-related mortality. (TIF $282 \mathrm{~kb}$ )

Additional file 2: Figure S2. The association between the total expenditures on health/GDP and the crude rates of (A) kidney cancer incidence and (B) kidney cancer-related mortality. The age-standardized rates of (C) kidney cancer incidence and (D) kidney cancer-related mortality (TIF 298 kb)

\section{Abbreviations}

ASR: Age-standardized rate; e/GDP: Total expenditures on health/gross domestic product; MIR: Mortality-to-incidence ratio; WHO: World Health Organization

\section{Funding}

There is no funding or grant support for this work.

\section{Availability of data and materials}

All the data were obtain from the global statistics of GLOBOCAN (http:// globocan.iarc.fr/Default.aspx).

\section{Research involving human participants}

All the data were obtained from the global statistics of GLOBOCAN (http:// globocan.iarc.fr/Default.aspx). This is a study of analytic epidemiology, and we did not perform any intervention on human participants.

\section{Informed consent}

All the data were obtain from the global statistics of GLOBOCAN (http:// globocan.iarc.fr/Defaultaspx). This is a study of analytic epidemiology that involved no intervention on human participants, so no informed consent was required.

\section{Authors' contributions}

Conception and design: WWS, TYH, SCW; acquisition of data: TYH; analysis and interpretation of data: WWS, WJC, CJH, CYH; drafting of the manuscript: $\mathrm{CJH}, \mathrm{CYH}$; critical revision of the manuscript: WWS, YLK, SLC; statistical analysis: WWS, TYH; supervision: WWS, SCW, SLC. All authors read and approved the final manuscript.

\section{Ethics approval and consent to participate}

Not applicable. All the data were obtained from the global statistics of GLOBOCAN (http://globocan.iarc.fr/Default.aspx). This is a study of analytic epidemiology, and we did not perform any intervention on human participants. We confirm that this study complies with national guidelines (http://law.moj.gov.tw/LawClass/LawAll.aspx?PCode=L0020162).

Consent for publication

Not applicable.

Competing interests

The authors declare that they have no competing interests. 


\section{Publisher's Note}

Springer Nature remains neutral with regard to jurisdictional claims in published maps and institutional affiliations.

\section{Author details}

'Department of Urology, Chung Shan Medical University Hospital, No.110, Sec. 1, Jianguo N. Rd., South Dist, Taichung City 402, Taiwan. ${ }^{2}$ School of Medicine, Chung Shan Medical University, No.110, Sec. 1, Jianguo N. Rd., South Dist, Taichung City 402, Taiwan. ${ }^{3}$ Institute of Medicine, Chung Shan Medical University, No.110, Sec. 1, Jianguo N. Rd., South Dist, Taichung City 402, Taiwan. ${ }^{4}$ Department of Medical Education, Chung Shan Medical University Hospital, No.110, Sec. 1, Jianguo N. Rd., South Dist, Taichung City 402, Taiwan. ${ }^{5}$ Department of Urology, National Taiwan University Hospital, No.95, Wenchang Rd., Shilin Dist, Taipei City 111, Taiwan.

Received: 13 November 2017 Accepted: 26 July 2018

Published online: 06 August 2018

\section{References}

1. Siegel RL, Miller KD, Jemal A. Cancer statistics, 2016. CA Cancer J Clin. 2016; 66(1):7-30.

2. Siegel RL, Miller KD, Jemal A. Cancer statistics, 2015. CA Cancer J Clin. 2015; 65(1):5-29.

3. Ferlay J, Soerjomataram I, Dikshit R, Eser S, Mathers C, Rebelo M, Parkin DM, Forman D, Bray F. Cancer incidence and mortality worldwide: sources, methods and major patterns in GLOBOCAN 2012. Int J Cancer. 2015;136(5): E359-86.

4. Torre LA, Bray F, Siegel RL, Ferlay J, Lortet-Tieulent J, Jemal A. Global cancer statistics, 2012. CA Cancer J Clin. 2015;65(2):87-108.

5. Rathmell WK, Godley PA, Rini BI. Renal cell carcinoma. Curr Opin Oncol. 2005;17(3):261-7.

6. Chen SL, Wang SC, Ho CJ, Kao YL, Hsieh TY, Chen WJ, Chen CJ, Wu PR, Ko

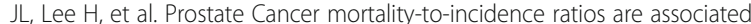
with Cancer care disparities in 35 countries. Sci Rep. 2017;7:40003.

7. Cordero-Morales A, Savitzky MJ, Stenning-Persivale K, Segura ER. Conceptual considerations and methodological recommendations for the use of the mortality-to-incidence ratio in time-lagged, ecological-level analysis for public health systems-oriented cancer research. Cancer. 2016;122(3):486-7.

8. Sunkara $V$, Hebert JR. The application of the mortality-to-incidence ratio for the evaluation of cancer care disparities globally. Cancer. 2016;122(3):487-8.

9. Adams SA, Choi SK, Khang L, Campbell DA, Friedman DB, Eberth JM, Glasgow RE, Tucker-Seeley R, Xirasagar S, Yip MP, et al. Decreased Cancer mortality-to-incidence ratios with increased accessibility of federally qualified health centers. J Community Health. 2015;40(4):633-41.

10. Sunkara V, Hebert JR. The colorectal cancer mortality-to-incidence ratio as an indicator of global cancer screening and care. Cancer. 2015;121(10):1563-9.

11. Wang CC, Tsai MC, Peng CM, Lee HL, Chen HY, Yang TW, Sung WW, Lin CC. Favorable liver cancer mortality-to-incidence ratios of countries with high health expenditure. Eur J Gastroenterol Hepatol. 2017;29(12):1397-401.

12. Tsai MC, Wang CC, Lee HL, Peng CM, Yang TW, Chen HY, Sung WW, Lin CC. Health disparities are associated with gastric cancer mortality-to-incidence ratios in 57 countries. World J Gastroenterol. 2017:23(44):7881-7.

13. Znaor A, Lortet-Tieulent J, Laversanne M, Jemal A, Bray F. International variations and trends in renal cell carcinoma incidence and mortality. Eur Urol. 2015;67(3):519-30.

14. Wang SC, Sung WW, Kao YL, Hsieh TY, Chen WJ, Chen SL, Chang HR. The gender difference and mortality-to-incidence ratio relate to health care disparities in bladder cancer: national estimates from 33 countries. Sci Rep. 2017;7(1):4360

15. Greiman AK, Rosoff JS, Prasad SM. Association of Human Development Index with global bladder, kidney, prostate and testis cancer incidence and mortality. BJU Int. 2017;120(6):799-807.

16. Capitanio U, Montorsi F. Renal cancer. Lancet. 2016;387(10021):894-906.

17. Siegel R, Ma J, Zou Z, Jemal A. Cancer statistics, 2014. CA Cancer J Clin. 2014:64(1):9-29.

18. Levi F, Ferlay J, Galeone C, Lucchini F, Negri E, Boyle P, La Vecchia C. The changing pattern of kidney cancer incidence and mortality in Europe. BJU Int. 2008;101(8):949-58.

19. Motzer RJ, MNA. J Natl Compr Canc Netw-2011-Motzer-960-77. J Natl Compr Cancer Netw. 2011;9:(9):960-77.
20. Marconi L, Desai MM, Ficarra V, Porpiglia F, Van Poppel H. Renal preservation and partial nephrectomy: patient and surgical factors. Eur Urol Focus. 2016;2(6):589-600.

21. Choi JE, You JH, Kim DK, Rha KH, Lee SH. Comparison of perioperative outcomes between robotic and laparoscopic partial nephrectomy: a systematic review and meta-analysis. Eur Urol. 2015;67(5):891-901.

22. Jang HJ, Song W, Suh YS, Jeong US, Jeon HG, Jeong BC, Jeon SS, Lee HM, Choi HY, Seo SI. Comparison of perioperative outcomes of robotic versus laparoscopic partial nephrectomy for complex RENAL tumors (RENAL nephrometry score of 7 or higher). Korean J Urol. 2014;55(12):808-13.

23. Simsek A, Yavuzsan AH, Colakoglu Y, Atar A, Sahin S, Tugcu V. Comparison of robotic and laparoscopic partial nephrectomy for small renal tumours. Arch Ital Urol Androl. 2017:89(2):93-6.

\section{Ready to submit your research? Choose BMC and benefit from:}

- fast, convenient online submission

- thorough peer review by experienced researchers in your field

- rapid publication on acceptance

- support for research data, including large and complex data types

- gold Open Access which fosters wider collaboration and increased citations

- maximum visibility for your research: over $100 \mathrm{M}$ website views per year

At BMC, research is always in progress.

Learn more biomedcentral.com/submissions 